\title{
Primarily nasal origin of exhaled nitric oxide and absence in Kartagener's syndrome
}

\author{
J.O.N. Lundberg*, E. Weitzberg**, S.L. Nordvall\#, R. Kuylenstierna\#", \\ J.M. Lundberg*, K. Alving
}

Primarily nasal origin of exhaled nitric oxide and absence in Kartagener's syndrome. J.O.N. Lundberg, E. Weitzberg, S.L. Nordvall, R. Kuylenstierna, J.M. Lundberg, K. Alving. CERS Journals Ltd 1994.

ABSTRACT: The exact origin of nitric oxide (NO) in exhaled air is not known. We wanted to further investigate at what site exhaled NO is produced and to determine whether children with Kartagener's syndrome exhibited altered levels of exhaled NO.

NO was measured by chemiluminescence technique in air sampled directly from the nose and in normally exhaled air of four children (2.5-13 years old) with Kartagener's syndrome, 20 healthy children, four healthy adults, and four conscious tracheostomized adults.

NO was almost absent ( $98 \%$ reduced) in air sampled directly from the nose in four children with Kartagener's syndrome $(4 \pm 1$ parts per billion (ppb)), compared to age-matched controls $(221+14(\mathrm{ppb}))$. Tracheostomized adult subjects had considerably higher NO values in nasally $(22 \pm 3 \mathrm{ppb})$ and orally $(14 \pm 2 \mathrm{ppb})$ exhaled air, compared to levels in air exhaled through the tracheostomy $(2 \pm 0 \mathrm{ppb})$. Treatment with intranasal corticosteroids for 14 days, or with antibiotics for 1 week, did not affect exhaled NO.

These results clearly show that, basically, all NO in exhaled air of healthy subjects originates from the upper respiratory tract, with only a minor contribution from the lower airways. Furthermore, the absence of nasal NO in children with Kartagener's syndrome could be of use as a simple noninvasive diagnostic test. Eur Respir J., 1994, 7, 1501-1504.

\begin{abstract}
*Division of Pharmacology, Dept of Physiology and Pharmacology, Karolinska Institute, Stockholm, Sweden. Depts of **Anaesthesiology and \#\#Oto-RhinoLaryngology Karolinska Hospital, Stockholm, Sweden. \#Dept of Paediatrics, St. Göran's Children's Hospital, Stockholm, Sweden.

Correspondence: J.O.N. Lundberg, Dept of Pharmacology, Karolinska Institute, S17177 Stockholm, Sweden

Keywords: Asthma, exhaled air, immotile cilia syndrome, Kartagener's syndrome, nasal mucosa, nitric oxide

Received: April 61994

Accepted after revision June 61994

This study was supported by grants from the Swedish Medical Research Council (project no. 10162 and 10354, the Swedish Tobacco Company, the Magnus Bergwall Foundation, AGA AB Medical Research Fund, the Th.C. Bergh Foundation, Swedish Environmental Health Agency, the Swedish Association against Asthma and Allergy, the Stockholm Association against Asthma and Allergy and Pharmacia Diagnostics.
\end{abstract}

The origin of exhaled nitric oxide (NO) in man has not been fully investigated, although recent findings indicate a major contribution from the nasal airways [1]. Elevated levels of NO were seen in exhaled air of asthmatics during oral but not nasal breathing [1]. In two subsequent studies [2,3], this difference was not accounted for, and great variations in NO values in exhaled air were reported. Furthermore, it is striking that exhaled air from intubated anaesthetized patients showed only low levels of NO [1]. We wanted to further examine the origin of NO in the human airways by measurements of exhaled NO at three different levels (nose, mouth and tracheostomy) in conscious subjects with a permanent tracheostomy. Furthermore, since NO synthase has been demonstrated in airway epithelial cells [4], and since NO has been suggested to take part in the regulation of ciliary motility [5], it was of interest to examine NO production in the airways of subjects with impaired ciliary function, such as patients with Kartagener's syndrome [6].

\section{Materials and methods}

The procedures employed in this study have been reviewed and approved by the local Ethics Committee. The following subjects were tested: 1) Healthy children (aged 3-13 yrs, n=20). 2) Children (aged 2.5-12 yrs, $\mathrm{n}=4$ ) with Kartagener's syndrome (a triad consisting of situs inversus, sinusitis and bronchiectasis). Three of these children were diagnosed by electron microscopy and respiratory cilia exhibited characteristic defects [6]. In one subject, no biopsy was taken, but this patient had clinical signs suggestive of Kartagener's syndrome, including situs inversus. 3) Nonsmoking subjects without lung disease but with a permanent tracheostomy due to tracheal stenosis or laryngeal cancer (aged 50-70 yrs, $n=4$ ), and fully capable of effortless breathing through the mouth, nose or tracheostomy. 4) Healthy, nonsmoking subjects (aged 29-40 yrs, n=4).

A chemiluminescence analyser (CLD 700; Eco Physics, Dürnten, Switzerland) sampling with a constant flow of 


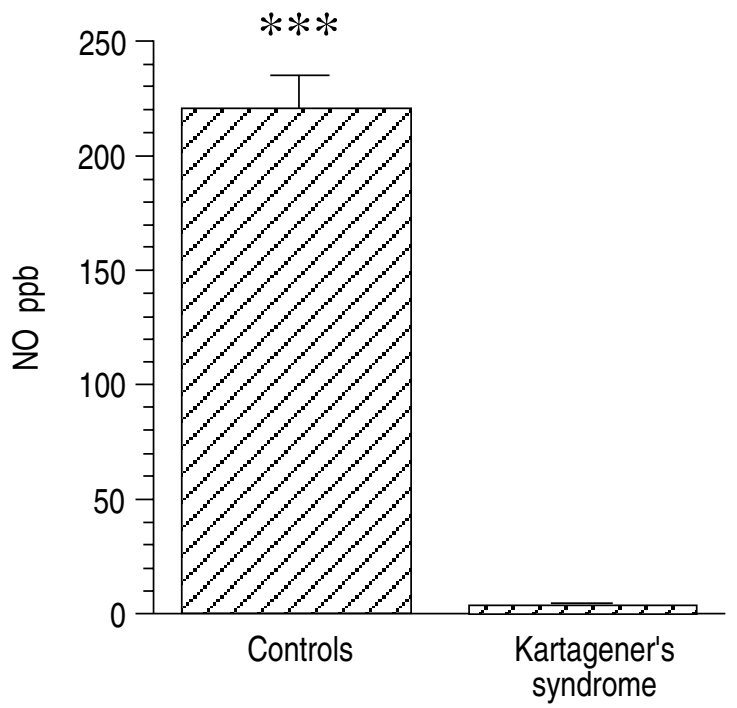

Fig. 1. - Steady-state NO levels (ppb) in air sampled directly from one nostril of healthy children (controls; $n=20$ ), and children with Kartagener's syndrome $(n=4)$. Data are presented as mean \pm SEM. ***: $\mathrm{p}<0.001$ compared to Kartagener's syndrome.

$0.8 \mathrm{l} \cdot \mathrm{min}^{-1}$ was used. The probe was connected to a nasal olive and gently introduced into the vestibulum of one nostril, avoiding contact with the nasal mucosa. The subjects were asked to breathe through the mouth, whilst the contralateral nostril was left open (direct nasal sampling). Plateau levels of NO were registered on a chart recorder. In the subjects with tracheostomy, NO was measured in exhaled air whilst breathing normal tidal volumes through the mouth, nose or the tracheostomy. Exhaled air was led into a Teflon tubing system and steady-state levels were recorded.
In this group, NO measurements were also made during a single-breath exhalation, with or without $15 \mathrm{~s}$ of breath-holding. The subjects performed a vital capacity manoeuvre through the nose, mouth or tracheostomy into Teflon tubings, and levels of exhaled NO were registered. In addition, NO levels during direct nasal sampling were measured before and after 14 days of intranasal treatment with budesonide (400 $\mu$ g per nostril daily; Rhinocort Turbuhaler ${ }^{\circledR}$, Tika AB, Sweden) in four healthy volunteers. Finally, similar measurements were made in 4 healthy volunteers before and after treatment with a penicillinase-stable antibiotic, perorally for 7 days (1.5 g.day ${ }^{-1}$; flucloxacillin, Heracillin ${ }^{\circledR}$, Astra AB, Sweden). NO concentrations in ambient air were $<2$ parts per billion (ppb) during all experiments.

One-way analysis of variance (ANOVA) with StudentNewman-Keuls Multiple Comparisons Test was used.

\section{Results}

When sampling air directly from the nose in healthy children, high NO levels were recorded (fig. 1). In contrast, in children with Kartagener's syndrome NO was almost absent (98\% lower; $\mathrm{p}<0.001)$ (fig. 1). Control levels of NO in air sampled directly from the nose of four healthy adults were $270 \pm 37 \mathrm{ppb}$ before treatment with corticosteroids, and $238 \pm 30 \mathrm{ppb}$ before antibiotic therapy. Neither local intranasal pretreatment with corticosteroids nor treatment with antibiotics significantly altered NO production in the nose $(241 \pm 29$ and $223 \pm 25$ $\mathrm{ppb}$, respectively). NO levels in normally exhaled air also remained unchanged by these treatments (not shown).

Exhaled NO levels in patients with a permanent tracheostomy were 10 times higher during nasal breathing a)

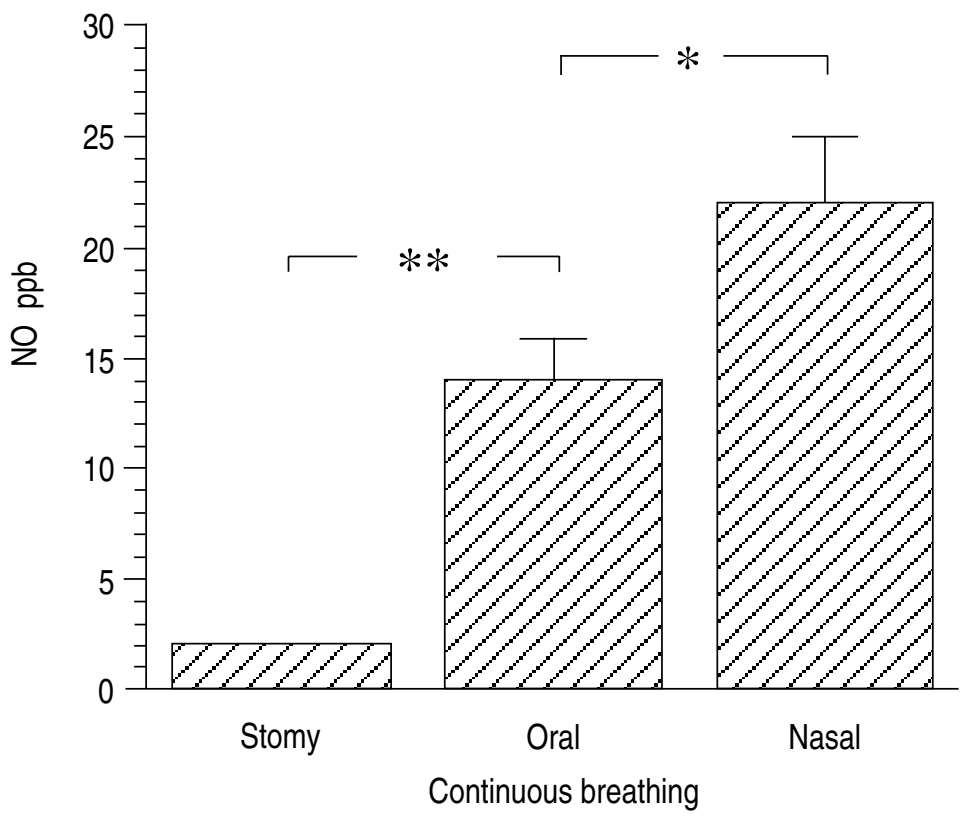

b)

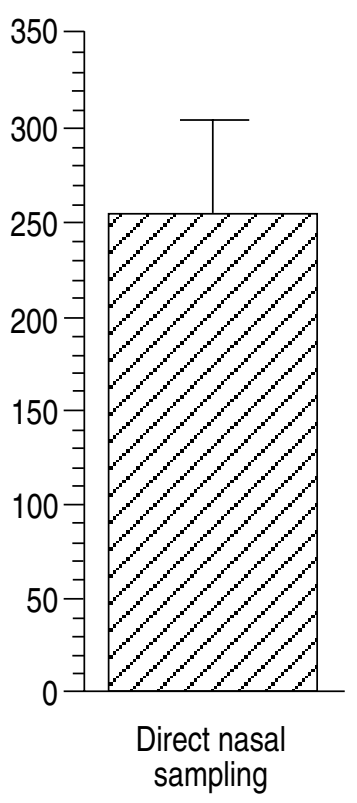

Fig. 2. - Steady-state NO levels (ppb) in exhaled air of four nonsmoking subjects with a tracheostomy (stomy). The subjects were: a) breathing continuously through the tracheostomy, mouth or nose; or b) air was sampled directly from one nostril. Data are presented as mean \pm sEm. $* \mathrm{p}<0.05$ and $* * \mathrm{p}<0.01$. 
a)

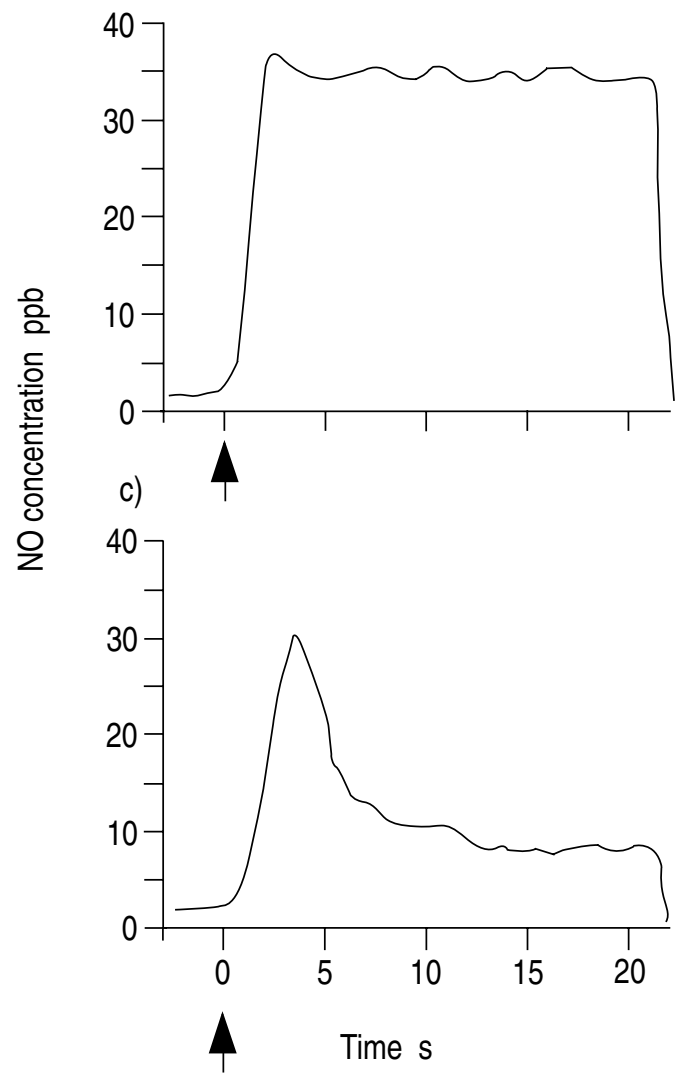

b)
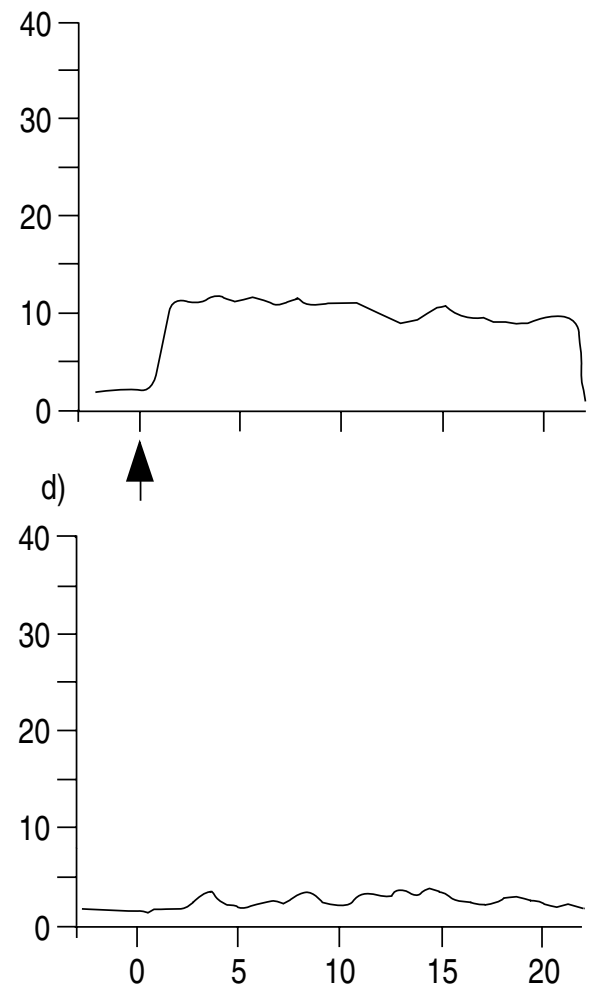

Time s

Fig. 3. - Original recordings from single-breath exhalations from total lung capacity of a conscious subject with a permanent tracheostomy. The arrow indicates start of exhalation. NO measurements were made over an exhalation time of $20 \mathrm{~s}$ during: a) exhalation through the nose without breath-holding; b) exhalation through the mouth without breath-holding; c) exhalation through the mouth after $15 \mathrm{~s}$ of breath-holding; d) and exhalation through the tracheostomy after $15 \mathrm{~s}$ of breath-holding.

$(22 \pm 3 \mathrm{ppb})$ and seven times higher during oral breathing (14 $\pm 2 \mathrm{ppb})$, compared to NO levels achieved when breathing via the tracheostomy $(2 \pm 0 \mathrm{ppb})$ (fig. $2 \mathrm{a})$. In the same subjects, high levels of NO were seen when sampling directly from one nostril (fig. 2b). In a single vital capacity exhalation through the nose or mouth without breath-holding, plateau NO levels of $35 \pm 8$ ppb during nasal exhalation (fig. 3a), and $7 \pm 2 \mathrm{ppb}$ during oral exhalation (fig. $3 b$ ), were reached. When exhaling through the mouth after $15 \mathrm{~s}$ of breath-holding, an initial peak of $30 \pm 10 \mathrm{ppb}$ was also noted (fig. 3c). However, when exhaling through the tracheostomy, the initial peak was absent and NO was constantly low ( $3 \pm 1 \mathrm{ppb})$, even after breath-holding (fig. 3d).

\section{Discussion}

Our results indicate that almost all NO in exhaled air originates from the upper airways in healthy subjects, with only a minor contribution from the lower airways, which is in contradiction to the findings of other studies $[7,8]$. Thus, conscious subjects with a tracheostomy exhibited only low values when breathing through the tracheostomy, whereas in orally and nasally exhaled air the same individuals showed considerably higher NO concentrations. Furthermore, single-breath measurements showed that the NO peak that was seen in orally exhaled air after breath-holding (fig. 3c) was in fact lost when exhaling through the tracheostomy (fig. 3d). This NO peak was probably caused by accumulation of NO from the upper airways during breath-holding. It might be argued that the low NO levels derived from the tracheostomy is caused by local epithelial changes, but this is unlikely since similar results were obtained when studying acute intubation in anaesthetized subjects [1].

Most of the NO from the upper airways is, thus, likely to be produced in the nasal cavity, since exhaled NO levels were also higher during nasal compared to oral breathing in all subjects, including healthy controls. Furthermore, direct nasal sampling yielded very high NO values. NO from the upper airways will follow the airstream with every inhalation and, thus, continuously flush the lower airways. It cannot yet be stated whether the concentrations are sufficient to have biological effects. However, recent studies have shown that inhaled $\mathrm{NO}$ at concentrations as low as $100 \mathrm{ppb}$ significantly decrease pulmonary vascular resistance in patients with pulmonary hypertension [9], indicating that nasally derived NO could be physiologically important in the lung and, thus, act as an airborne, or "aerocrine" factor. NO also has bacteriostatic [10] and antiviral [11] properties, and 
nasally-derived NO can possibly participate in the unspecific primary mucosal defence line against infections.

Kartagener's syndrome is referred to as an "immotile cilia syndrome". It is a triad of bronchiectasis, recurrent rhinosinusitis and situs inversus. There are, currently, no reliable noninvasive diagnostic methods for this disease and the correct diagnosis is often delayed many years, possibly causing irreversible pulmonary damage [6]. Therefore, the finding that four children with Kartagener's syndrome had almost undetectable NO concentrations in nasally-derived air is most interesting, since NO measurements, which are noninvasive and can easily be performed even in infants, could be of help in the early diagnosis.

There are two possible explanations for the low nasal NO values in Kartagener's syndrome. Either the production of NO is absent, or the diffusion of NO into the airway lumen is reduced in some way. The latter could be due to impaired mucociliary clearance [6], but this is unsatisfactory as a sole explanation, since in asthmatic subjects with severe nasal congestion and secretion more prominent than in the children with Kartagener's syndrome, nasal NO values are high (unpublished data).

If the low NO levels are due to a reduced production, this could be explained by a deficient NO synthesis in the superficial structures of the nasal airways. Ciliated epithelial cells normally contain NO synthase [4], and NO may be involved in the regulation of ciliary movements [5], indicating that the ciliary dysfunction and the impaired NO synthesis seen in Kartagener's syndrome could be interrelated. It remains to be determined whether stimulation of NO production may be useful in the treatment of these patients. The NO synthase in the nasal airways is likely to be of a constitutive isoform rather than an inducible one, since local treatment with corticosteroids, that are known to inhibit the inducible enzyme [10], did not affect NO levels in exhaled air. However, the presence of an inducible NO synthase cannot be excluded, since this isoform has been demonstrated in normal tracheobronchial epithelium [4].

An alternative explanation to the low NO levels in Kartagener's syndrome could be that bacteria are involved in the synthesis of NO in normal nasal mucosa. Some bacteria are known to produce NO from nitrite [12], and patients with Kartagener's syndrome are often treated with antibiotics. Therefore, the low NO production could be explained by differences in the nasal bacterial composition. However, only one of the children with Kartagener's syndrome had been on antibiotic therapy within two months before NO measurements. Moreover, antibiotic treatment (the same as that used in the one child with Kartagener's syndrome) had no effect on nasal NO values in healthy subjects.

In conclusion, in the airways of healthy individuals NO seems to be produced predominantly in the upper airways. If this large production is not taken into account during measurements, it may blunt changes in NO synthesis in the lower airways [1]. In Kartagener's syndrome, nasal NO production is almost absent, which may be of help in the diagnosis of this disease and also in understanding the role of airway derived NO.

\section{References}

1. Alving K, Weitzberg E, Lundberg JM. Increased amounts of nitric oxide in exhaled air of asthmatics. Eur Respir $J$ 1993; 6: 1368-1370.

2. Kharitonov SA, Yates D, Robbins RA, et al. Increased nitric oxide in exhaled air of asthmatic patients. Lancet 1994; 343: 133-135.

3. Persson MG, Zetterström O, Agrenius V, et al. Singlebreath nitric oxide measurements in asthmatic patients and smokers. Lancet 1994; 343: 146-147.

4. Kobzik L, Bredt DS, Lovenstein CJ, et al. Nitric oxide synthase in human and rat lung: immunocytochemical and histochemical localization. Am J Respir Cell Mol Biol 1993; 9: 371-377.

5. Jain B, Rubenstein I, Robbins RA, et al. Modulation of airway epithelial cell ciliary beat frequency by nitric oxide. Biochem Biophys Res Commun 1993; 191: 8388.

6. Levison H, Minsdorff CM, Chao J, et al. Pathophysiology of the ciliary motility syndromes. Eur J Respir Dis 1983; 64 (Suppl. 127): 102-116.

7. Borland C, Cox Y, Higenbottam T. Measurement of exhaled nitric oxide in man. Thorax 1993; 48: 1160-1162.

8. Persson MG, Wiklund NP, Gustavsson LE. Endogenous nitric oxide in single exhalations and the change during exercise. Am Rev Respir Dis 1993; 148: 1210-1214.

9. Puybasset L, Rouby JJ, Mourgeon E, et al. Inhaled NO in ARDS: dose-response curves. Br J Anaesth 1994; 72 (Suppl. 1): 56 (A107).

10. Moncada S, Palmer RMJ, Higgs EA. Nitric oxide: physiology, pathophysiology, and pharmacology. Pharmacol Rev 1991; 43: 109-141.

11. Croen KD. Evidence for an antiviral effect of nitric oxide. J Clin Invest 1993; 91: 2446-2452.

12. Ji X, Hollocher TC. Nitrate reductase of Escherichia coli as a NO-producing nitrite reductase. Biochem Arch 1989; 5: 61-66. 